\title{
Evaluating Correlations between a Seaport and Its Dry Ports: Case Study of Xiamen Port in China
}

\author{
Jihong Chen $\left(\mathbb{D},{ }^{1,2}\right.$ Yijie Fei ${ }^{(D)},{ }^{1}$ Fangwei Zhang $\left(\mathbb{D},{ }^{1}\right.$ and Chutao Jing ${ }^{1}$ \\ ${ }^{1}$ College of Transport and Communications, Shanghai Maritime University, Shanghai 201306, China \\ ${ }^{2}$ Commercial College, Xian International University, Xian 710077, China \\ Correspondence should be addressed to Fangwei Zhang; fangweizhangsmu@163.com
}

Received 24 January 2018; Accepted 20 May 2018; Published 25 June 2018

Academic Editor: Ricardo López-Ruiz

Copyright (c) 2018 Jihong Chen et al. This is an open access article distributed under the Creative Commons Attribution License, which permits unrestricted use, distribution, and reproduction in any medium, provided the original work is properly cited.

\begin{abstract}
As bridges connecting seaports and their hinterland, dry ports serve to expand the hinterland and increase cargo sources of seaports, rendering efficient international logistics circulation in hinterland areas possible. The roles of dry ports have attracted increasing attention from various ocean shipping countries. Seaports and dry ports possess complementary functions and increasingly close interactions. The paper builds an assessment indicator system on correlations between seaports and dry ports and a two-stage grey relational analysis (GRA) method through collating dry port-related literature to facilitate quantitative studies on the correlations between seaports and dry ports, namely, using two quantitative indicators of Deng's correlation and absolute correlation to assess and determine the correlations in the development of seaports and dry ports. The paper then carries out case studies on Xiamen Port and its six dry ports to verify the effectiveness of the method and model in the paper. The study results show that Xiamen Port has very high region-varying correlations with its hinterland dry ports. Dry port development not only depends on their shipment volume indicators, but also significantly correlated with their economic indicators, and the hinterland economic indicators become key factors driving the fast development of a seaport. The analyzing method in the paper is conducive for government departments and relevant stakeholders to formulate superior policies and provide theoretical bases for the development of correlations between seaports and their dry ports.
\end{abstract}

\section{Introduction}

A coastal seaport, through establishing supporting dry ports in its inland areas, can extend shipping logistics services to its economic hinterland, which can not only bring more cargo sources to the seaport, but also indirectly expand its capacity. The cooperation between a seaport and its dry ports can provide a fast sea-going channel for hinterland areas, being a key to accelerate development of hinterlandbased logistics services. Dry ports can well solve seaports' insufficient reserved land areas [1] and act as inland logistic connectors between railways and seaports [2]. Boosted by global economic integration and inland-oriented logistics services, seaports, and dry ports enjoy increasingly closer ties. Therefore, it is necessary to establish an indicator system to assess the correlations between seaports and dry ports and carry out studies on their correlations, so as to further promote their cooperation.
Dry ports, as part of seaports' logistics services, play a key role in seaport-related supply chains and connect seaports with its hinterland to form an integral network system (see Figure 1). In the figure, seaports, acting as the starting point of waterborne transportation, interact with dry ports. Hinterland areas transport cargos via roads, while dry ports play a key role to connect seaports and hinterland areas to collect inland cargos and dispatch them to seaports for ocean shipping. The paper aims to study the correlations between seaports and dry ports.

The remainder of the paper is organized as follows. Following a relevant literature review, knowledge gaps are identified in Section 2. Section 3 of this paper establishes an assessment indicator system on correlations between a seaport and its dry ports and uses the two-stage GRA method for the quantitative study on correlations between a seaport and its dry ports. Section 4 provides case studies on Xiamen Port and its six dry ports, using Deng's correlation and 


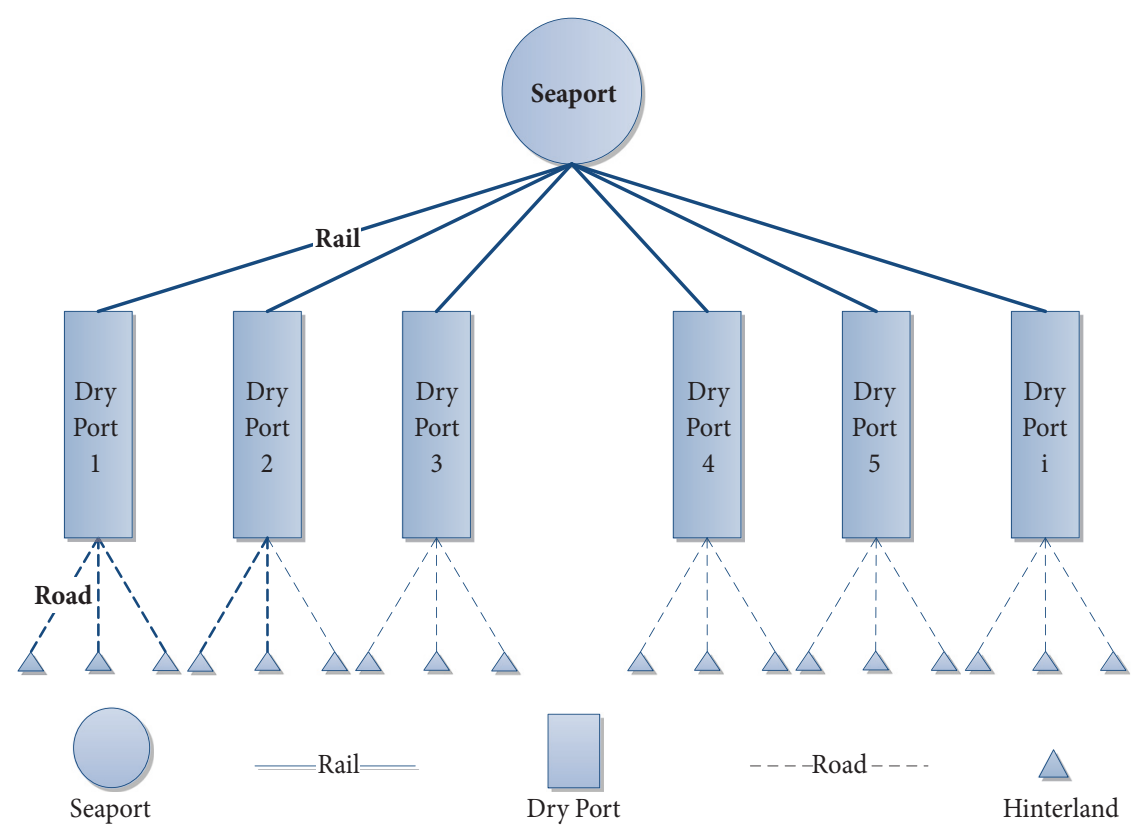

FIGURE 1: Correlations between a seaport and its dry ports and hinterlands.

absolute correlation as the bases for the assessment, with superior policies proposed for developing a seaport and its dry ports. A summary and prospect are given at the end of the paper.

\section{Literature Review}

The correlations between a seaport and its dry ports in global maritime transportation have long been a focus in the international shipping community. A number of previous studies have addressed the correlations of global maritime transportation, with a summary of these academic works presented below. Much existing academic research has been focusing on a dry port's connotation and its site selection as well as the correlations between a seaport and its dry ports.

Researchers have not yet reached a consensus regarding a dry port's connotation. One opinion holds that a dry port is a measure to solve the lack of reserved land areas at a seaport [1]. Some other scholars hold that a dry port is just a logistic point [14]. Another representative opinion holds that a dry port is the transfer of a container seaport's gate to its inland area and the dry port is a part of the seaport $[15,16]$.

Another key issue in seaport and dry port study is a dry port's site selection, in which large numbers of mathematical methods are used, including principal component analysis (PCA) [17], factor analysis [18], analytic hierarchy process (AHP) [19-23], and fuzzy clustering method [24-29]. Among these methods, the fuzzy clustering method is most widely used, and a representative is Zhang's study on the site selection among 34 dry port candidate sites by using Cmeans fuzzy clustering [24]. Zeng and Wang qualitatively selected cargo source cities as objects for research and used the systematic fuzzy clustering method for dry ports' site distribution and hierarchy classification [26]. Zhang and Han conducted clustering analysis on the seaport's 78 prefecture-level hinterland cities against the industry transfer background and shortlisted 17 cities for dry port construction [28].

Different scholars have studied on the correlations between seaports and dry ports from different perspectives, but they did not conduct quantitative analyses. The aspects of their studies include transportation costs and profits [12, 30$33]$, port productivity [30, 32], environmental quality [12, $31,33]$, port investment [34], port scale [35-37], capacity of combined transport systems [35, 38], and consumption level in the region [32]. These indicators have played varied roles for studying correlations between seaports and dry ports, but a correlation assessment indicator system fails to be established, and quantitative study on correlations remains absent.

In summary, relevant literature to date mainly covers a dry port's connotation, its site selection, and the correlations between seaports and dry ports. However, not much quantitative research has been conducted on the correlations between seaports and dry ports, and relevant selected assessment indicator systems are not proper enough; namely, there is no appropriate quantitative assessment method available. Therefore, this paper aims to solve three issues: (1) improve the seaport and dry port interaction indicator system, (2) establish a quantitative analyzing tool for studying correlations between seaports and dry ports, two-stage GRA method, and (3) put forward relevant policies for joint development of seaports and dry ports to promote interactive development of seaports and their dry ports.

\section{Methodology}

The GRA method is widely used for studying correlations of a system with the restriction of multiple factors. This method can well make up for data deficiencies and irregular data 


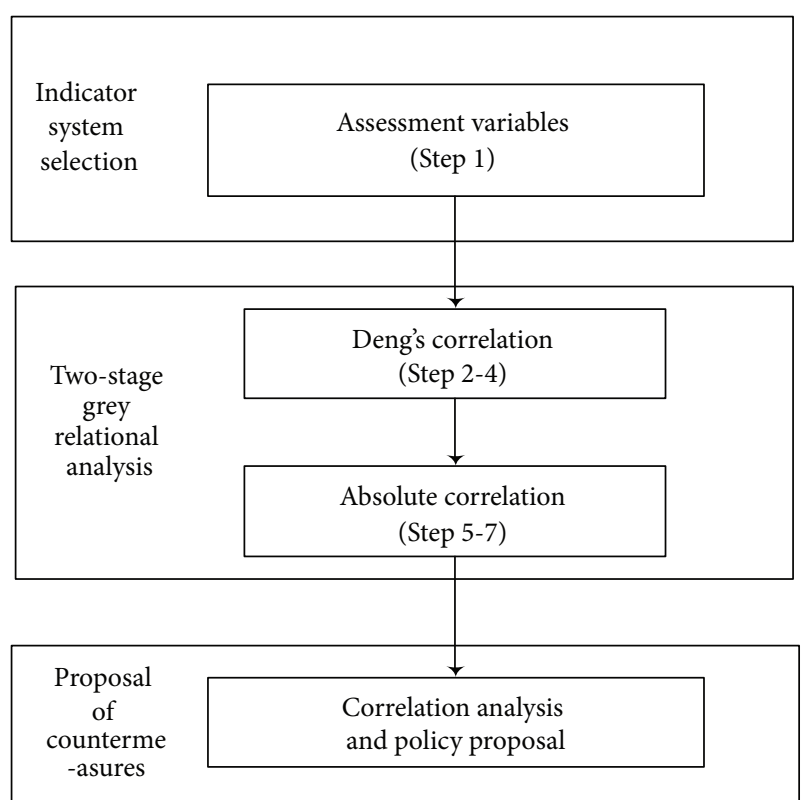

FIGURE 2: Framework of the two-stage GRA (grey relational analysis) method proposed in this paper.

distribution without mathematical statistics, so that it can identify primary and secondary factors in the development course of things despite the incomplete and uncertain information. The grey correlation implies the degree of association between two elements. If their evolving trends are highly consistent, they have relatively high correlations, and vice versa.

3.1. Basic Framework of the Model Analysis. The study framework of using the two-stage GRA method to assess the correlations between a seaport and its dry ports in this paper can be classified into three modules (see Figure 2). Module 1 is to build an indicator system to assess the correlations between a seaport and its dry ports and choose generally accepted indicators through collating relevant literature. Module 2 is to establish a method for the study, namely, the two-stage GRA method, by using Deng's correlation in the first stage to measure and calculate the overall correlations between a seaport and its dry ports, and the absolute correlation in the second stage to measure and calculate various specific indicators' correlations between a seaport and its dry ports. Module 3 is to analyze relevant values' correlations and put forward macropolicies after study results come out.

\subsection{Main Steps for Model Formulation}

Step 1 (assessment variables and definition of sequences). This paper reviewed recent academic papers concerning factors affecting the correlation between seaports and their dry ports. Assessment indicators were selected from two perspectives: seaport indicators and dry port indicators (see Figure 3). There are a total of two seaport indicators, namely, a port's cargo throughput and container throughput, the former referring to the loaded/unloaded cargo volume for waterborne transport at a port within a designated period of time, and the latter referring to the total number of incoming and outgoing containers at a port within a designated period of time. There are a total of seven dry port indicators for dry port assessment, namely, the regional GDP of a dry port's hinterland, the regional GDP of secondary industries, the regional GDP third industries, the total cargo imports, the total cargo exports, the total cargo volume for transport, and the cargo volume for railway transport. The annual import and export trade values of hinterland cities of a dry port and the cities' annual GDP can reflect the degree of economic development of the hinterland, while the economic power will directly or indirectly influence the region's commodity demand and cargo transport demand. Transport volume is an indicator of a collection, distribution, and transportation system which determines the convenience of a cargo collection and distribution port. When cargo collection and distribution are smooth, the cargo turnaround is short, which constitutes strong attractiveness to cargo sources.

The chosen indicators' literature source is as follows (see Table 1). And the definition of seaport sequence $X$ and dry port sequence $D$ are as follows:

$$
\begin{aligned}
X & =\left(x_{t}(1), x_{t}(2) \ldots x_{t}(k)\right), \\
k & =1,2, \ldots l ; t=1,2, \ldots s \\
D=\left(d_{i t}(1), d_{i t}(2) \ldots d_{i t}(j)\right), & \\
i=1,2, \ldots m ; j & =1,2, \ldots n ; t=1,2, \ldots s
\end{aligned}
$$

$x_{t}(k)$ represents the $k$ indicator of seaport at the time point of $t$ and $d_{i t}(j)$ represents the $j$ indicator of the $i$ dry port at the time point of $t$.

Step 2 (standardization of indicators). The evaluation indicators are normalized. The evaluation indicators have different dimensions and orders of magnitude. To remove the influence of dimensions, the original indicators are normalized. In this paper, mean value normalization preprocessing method was applied to evaluation indicators. The standardization of seaport sequence $\mathrm{X}$ is calculated using

$$
x_{\mathrm{t}}^{\prime}(k)=\frac{x_{t}(k)-\mu}{\sigma}
$$

where $x_{\mathrm{t}}^{\prime}(k)$ is the standardization processing result, $x_{t}(k)$ denotes the raw data, $\mu$ is mean of the same indicator values, and $\sigma$ represents standard deviation. The same procedure may apply to dry port sequence $\mathrm{D}$, and $d_{i t}^{\prime}(j)$ is the standardization processing result.

Step 3 (grey relational coefficient). The grey relational coefficient between the $\mathrm{k}$ indicator of the seaport and the $\mathrm{j}$ indicator of $i$ dry port at the time point of $t$ can be calculated by

$$
\begin{array}{r}
\gamma_{k i j}(t) \\
=\frac{\min _{k} \min _{j}\left|x_{t}^{\prime}(k)-d_{i t}^{\prime}(j)\right|+\varphi \max _{k} \max _{j}\left|x_{t}^{\prime}(k)-d_{i t}^{\prime}(j)\right|}{\left|x_{t}^{\prime}(k)-d_{i t}^{\prime}(j)\right|+\varphi \max _{k} \max _{j}\left|x_{t}^{\prime}(k)-d_{i t}^{\prime}(j)\right|} \\
\mathrm{k}=1,2, \ldots \mathrm{l} ; \mathrm{j}=1,2, \ldots \mathrm{n}
\end{array}
$$




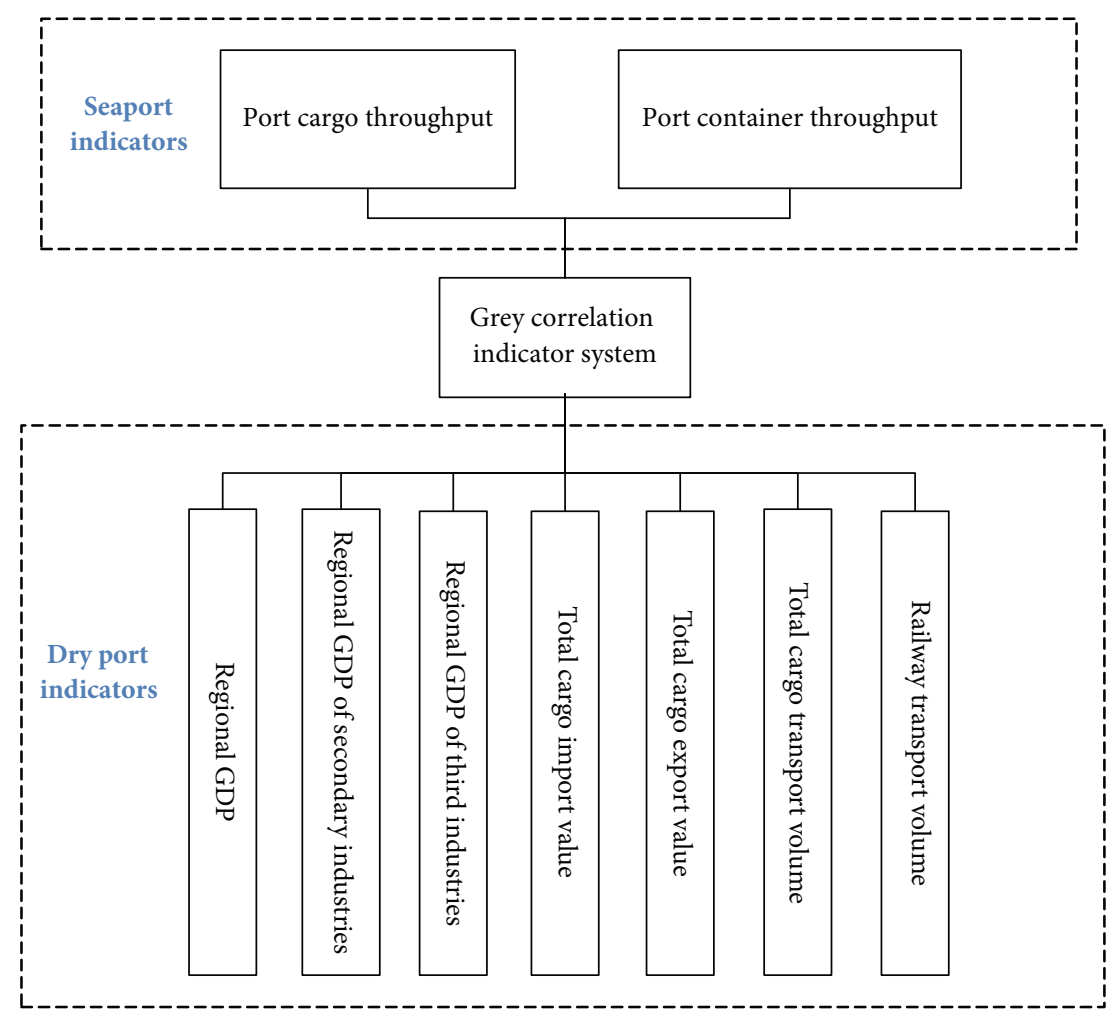

FIGURE 3: Assessment variables of seaports and their dry ports.

where $\gamma_{k i j}(t)$ represents the coefficient of $x t(k)$ and $\operatorname{dit}(j)$ at the time point of t. $\varphi$ is known as the distinguish coefficient. The value of $\varphi$ ranges from 0 to 1 , with the value generally taken as 0.5 .

Step 4 (grey relational grade). After the calculation of the entire grey relational coefficient $\gamma_{k i j}(t)$, the grey relational grade can be calculated by

$$
\gamma\left(x, d_{i}\right)=\frac{1}{s} \sum_{\mathrm{t}=1}^{s} \sum_{k=1}^{l} \sum_{j=1}^{n} \gamma_{k i j}(t) \quad \mathrm{t}=1,2, \ldots \mathrm{s}
$$

In (4), $\gamma\left(x, d_{i}\right)$ is the grey relational grade between the seaport and i dry port.

Step 5 (starting-point annihilating values). The startingpoint annihilating value of $\mathrm{k}$ indicator of the seaport is calculated using

$$
\begin{aligned}
& {\left[x_{1}^{\prime}(k), x_{2}^{\prime}(k) \ldots x_{t}^{\prime}(k) \ldots x_{s}^{\prime}(k)\right]} \\
& \quad=\left[\frac{x_{1}(k)}{x_{1}(k)}, \frac{x_{2}(k)}{x_{1}(k)} \ldots \frac{x_{t}(k)}{x_{1}(k)} \ldots \frac{x_{s}(k)}{x_{1}(k)}\right] \\
& \quad t=1,2 \ldots s \\
& {\left[x_{1}^{\prime \prime}(k), x_{2}^{\prime \prime}(k) \ldots x_{t}^{\prime \prime}(k) \ldots x_{s}^{\prime \prime}(k)\right]=\left[x_{1}^{\prime}(k)\right.} \\
& \quad-x_{1}^{\prime}(k), x_{2}^{\prime}(k)-x_{1}^{\prime}(k), \ldots x_{t}^{\prime}(k) \\
& \left.-x_{1}^{\prime}(k) \ldots x_{s}^{\prime}(k)-x_{1}^{\prime}(k)\right] \quad \mathrm{t}=1,2, \ldots \mathrm{s}
\end{aligned}
$$

In (6), $x_{t}^{\prime \prime}(k)$ represents the starting-point annihilating values of the $k$ indicator of the seaport at the time point of $t$. The same procedure may apply to $j$ indicator of dry port, and $d_{i t}^{\prime \prime}(j)$ is the starting-point annihilating values of $j$ indicator of $\mathrm{i}$ dry port at the time point of $\mathrm{t}$.

Step 6 (grey absolute correlation grade).

$$
\begin{aligned}
\gamma^{\prime} & \left(x(k), d_{i}(j)\right) \\
& =\frac{1+\left|\sum_{t=2}^{s-1} x_{t}^{\prime \prime}(k)+(1 / 2) x_{s}^{\prime \prime}(k)\right|+\left|\sum_{t=2}^{s-1} d_{i t}^{\prime \prime}(j)+(1 / 2) d_{i s}^{\prime \prime}(j)\right|}{1+\left|\sum_{t=2}^{s-1} x_{t}^{\prime \prime}(k)+(1 / 2) x_{s}^{\prime \prime}(k)\right|+\left|\sum_{t=2}^{s-1} d_{i t}^{\prime \prime}(j)+(1 / 2) d_{i s}^{\prime \prime}(j)\right|+\left|\sum_{t=2}^{s-1}\left(d_{i t}^{\prime \prime}(j)-x_{t}^{\prime \prime}(k)\right)+(1 / 2)\left(d_{i s}^{\prime \prime}(j)-x_{s}^{\prime \prime}(k)\right)\right|}
\end{aligned}
$$




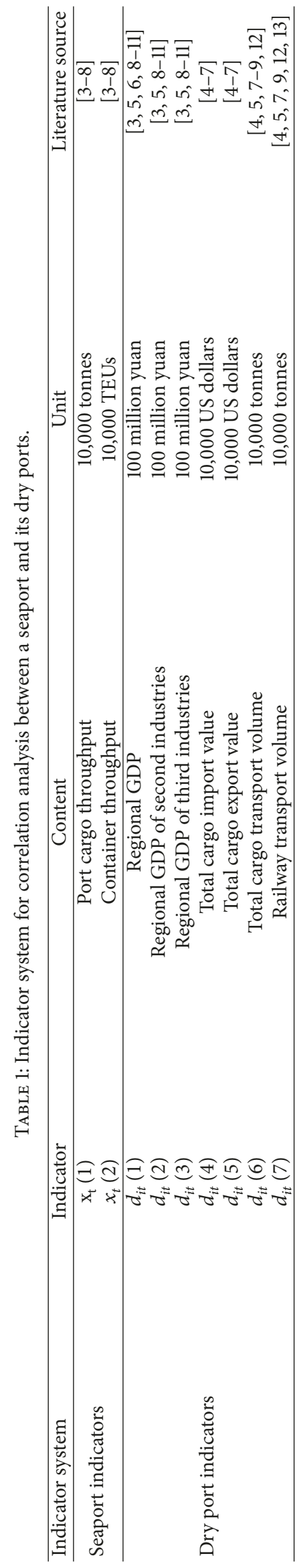




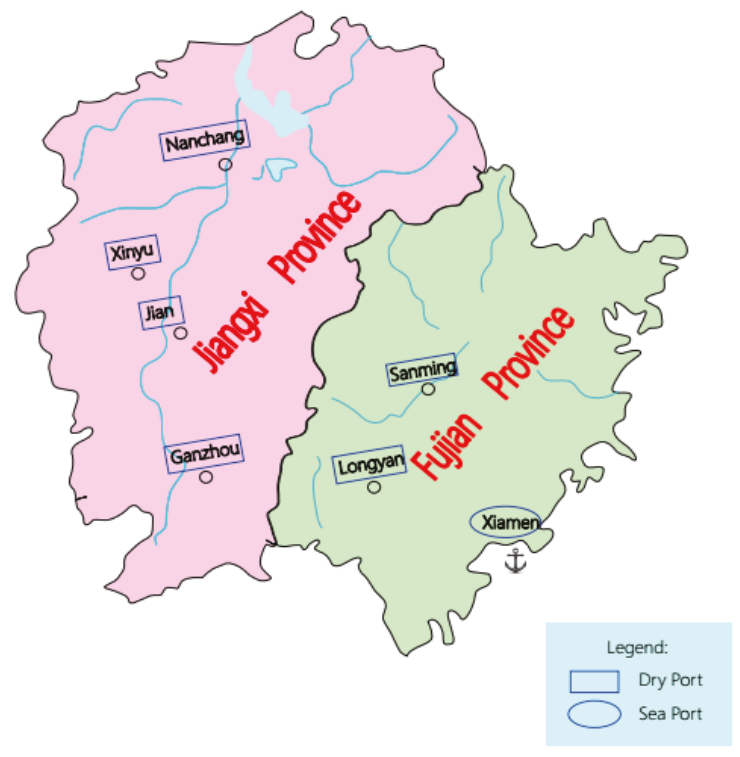

Figure 4: A diagram of Xiamen Port and her dry ports.

In (7), $\gamma^{\prime}\left(x(k), d_{i}(j)\right)$ is the grey absolute correlation grade between the $k$ indicator of the seaport and $j$ indicator of $i$ dry port.

Step 7 (ranking the $\mathrm{j}$ indicator of dry port).

$$
\gamma^{\prime}(x, d(j))=\frac{1}{m l} \sum_{k=1}^{l} \sum_{i=1}^{m} \gamma^{\prime}\left(x(k), d_{i}(j)\right)
$$

In $(8), \gamma^{\prime}(x, d(j))$ represents the grey absolute correlation grade between the seaport and indicator $j$. Then the ranking of dry port indicator from results obtained from (8) could be performed.

\section{Case Study}

This section illustrates case studies on correlations between China's Xiamen Port and its six dry ports located in Fujian and Jiangxi provinces. Among them, Sanming and Longyan dry ports are located in central and southern areas of Fujian province, respectively, and the other four dry ports are all situated in Jiangxi province, Nanchang in northern Jiangxi, Ganzhou in southern Jiangxi, and Xinyu and Jian in central Jiangxi. Different from coastal seaports, the six dry ports are all in inland areas.

4.1. Descriptive Analysis of the Case Studied. The geographical location of Xiamen Port is shown in Figure 4. Being an important import and export port along China's southeastern coast, Xiamen Port is surrounded by hilly areas in southern Fujian and has very inconvenient road connections with its inland areas, and its business environment is further harshened by the competition from its neighboring seaports. In addition, the diversion of a large amount of its hinterland cargo sources also hinders the seaport's development.
Therefore, it is imperative to establish dry ports as an effective measure to attract cargo sources. It can be seen from Figure 4 that Xiamen Port's six dry ports are nearly evenly distributed across Fujian and Jiangxi provinces, but there is no dry port capable of cargo collection and distribution in northwestern Fujian and northeastern Jiangxi in the neighboring district.

4.2. Data Collection. According to the assessment indicator system on correlations between Xiamen Port and its dry ports in Section 3, relevant data on Xiamen Port and its dry ports, including regional GDP, regional GDP of secondary and third industries, and cargo import and export values, was collected based on Fujian Statistical Yearbook and Jiangxi Statistical Yearbook as well as the official websites of statistical bureaus in various dry port cities. The collected data was mentioned in Section 3 from 2003 to 2014 . We have selected these 12 year's data for the case study, with Y1 to Y12 representing 2003 to 2014, respectively. In order to obtain accurate statistical data for the seaport and its dry ports, the data was taken from almanacs and online information released directly by government authorities.

4.3. Gray Relational Analysis. The grey relational analysis consists of Deng's correlation in Section 4.3.1 and absolute correlation in Section 4.3.2.

4.3.1. Grey Relational Correlation Grade Calculation. Deng's correlation is used to assess the overall correlations between Xiamen Port and its dry ports. The paper takes Sanming Dry Port as an example to conduct step-by-step analysis based on Deng's correlation, and only final calculation results are given for other dry ports. We suppose the year 2003 corresponds to $t=1$; then the follow-up sequential numbers of $t$ represent its subsequent years. The raw data of various indicators for Xiamen Port and Sanming Dry Port from 2003 to 2014 is shown in Table 2. First, use the above-mentioned Formula (2) for the nondimensionalization of the raw data, and the results are shown in Table 3. Calculate the absolute values of the differences of all the corresponding indicators between Xiamen Port and Sanming Dry Port to get the maximum and minimum values, $\Delta \max$ and $\Delta \min$ (see Table 4). Enter the two values into Formula (3) and use Formula (4) to get the indicators' Deng's correlation between Xiamen Port and Sanming Dry Port, as shown in Table 5.

Using the same method, we can get Deng's correlations for other five dry ports during the selected years.

The radar chart shows Deng's correlations between Xiamen Port and its dry ports from 2003 to 2014 (see Figure 5). Xiamen Port had relatively strong correlations with its dry port-located hinterlands and, in some periods, their correlations showed short-time declines but maintained an increasing trend overall. With the seaport's transport network extending into inland areas, various seaports along southeastern coasts in Fujian province will introduce preferential policies to attract cargo sources, making the competition among dry ports for hinterland cargo sources even fiercer. Priority in development of dry ports with advantageous positions is a key for seaports to expand hinterland radiation and increase cargo sources. 


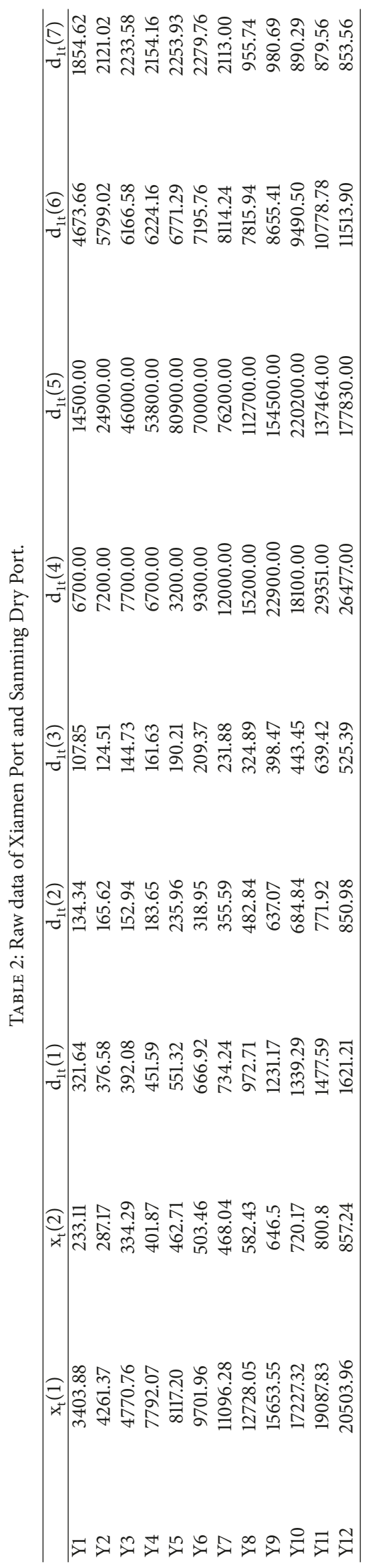




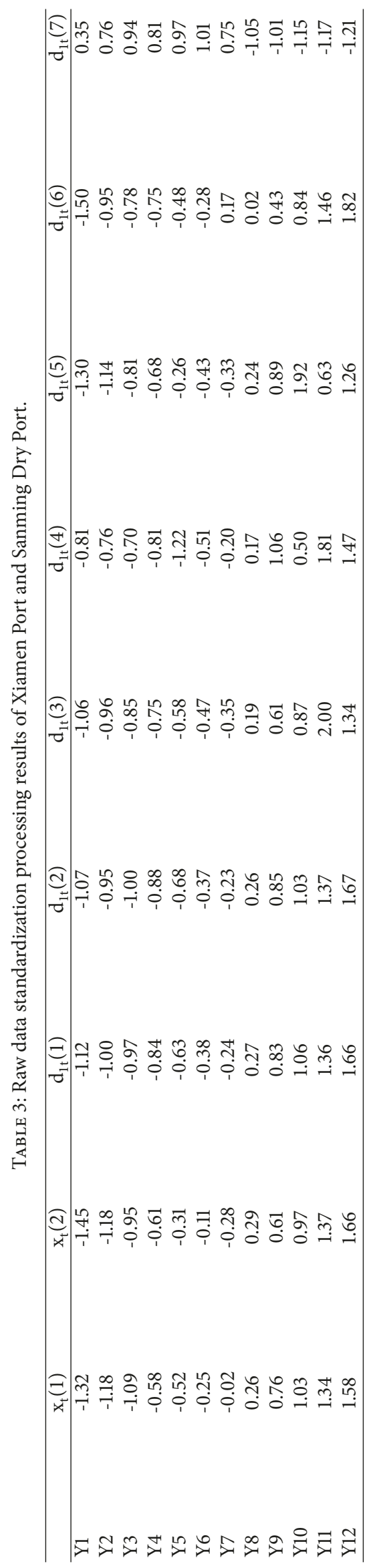




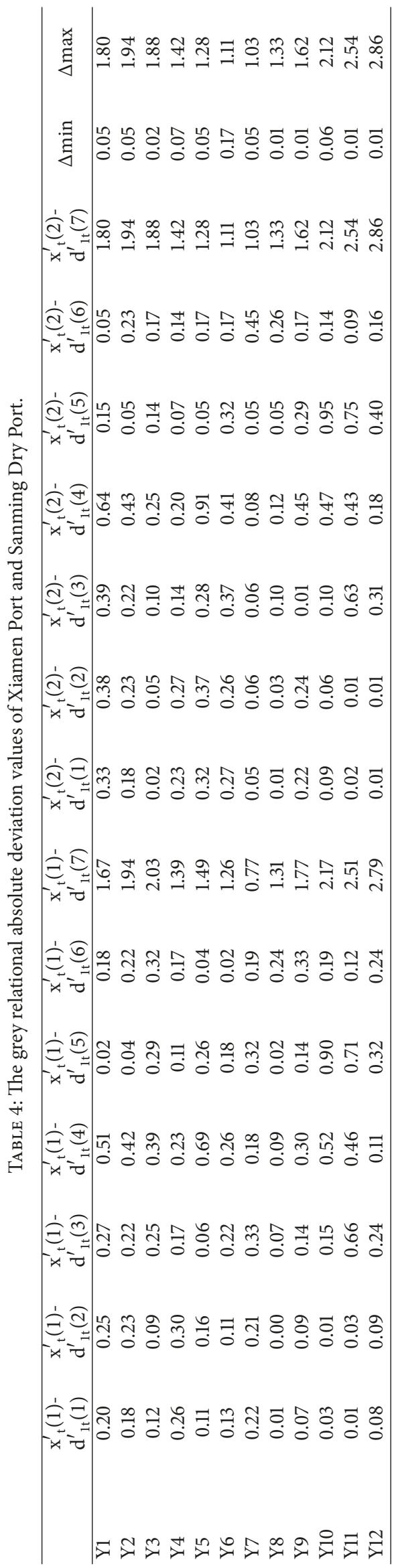




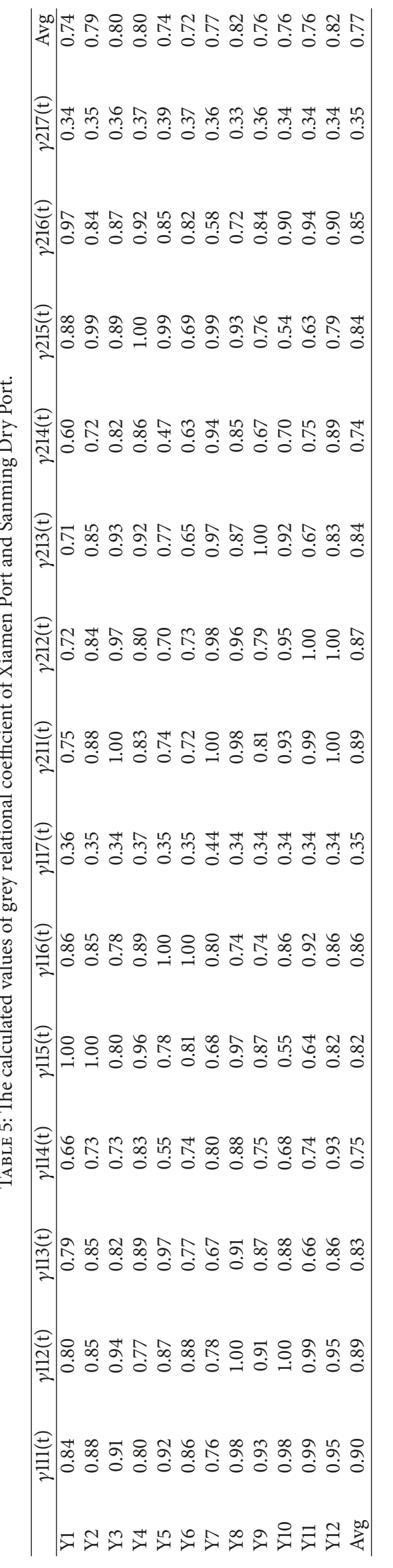




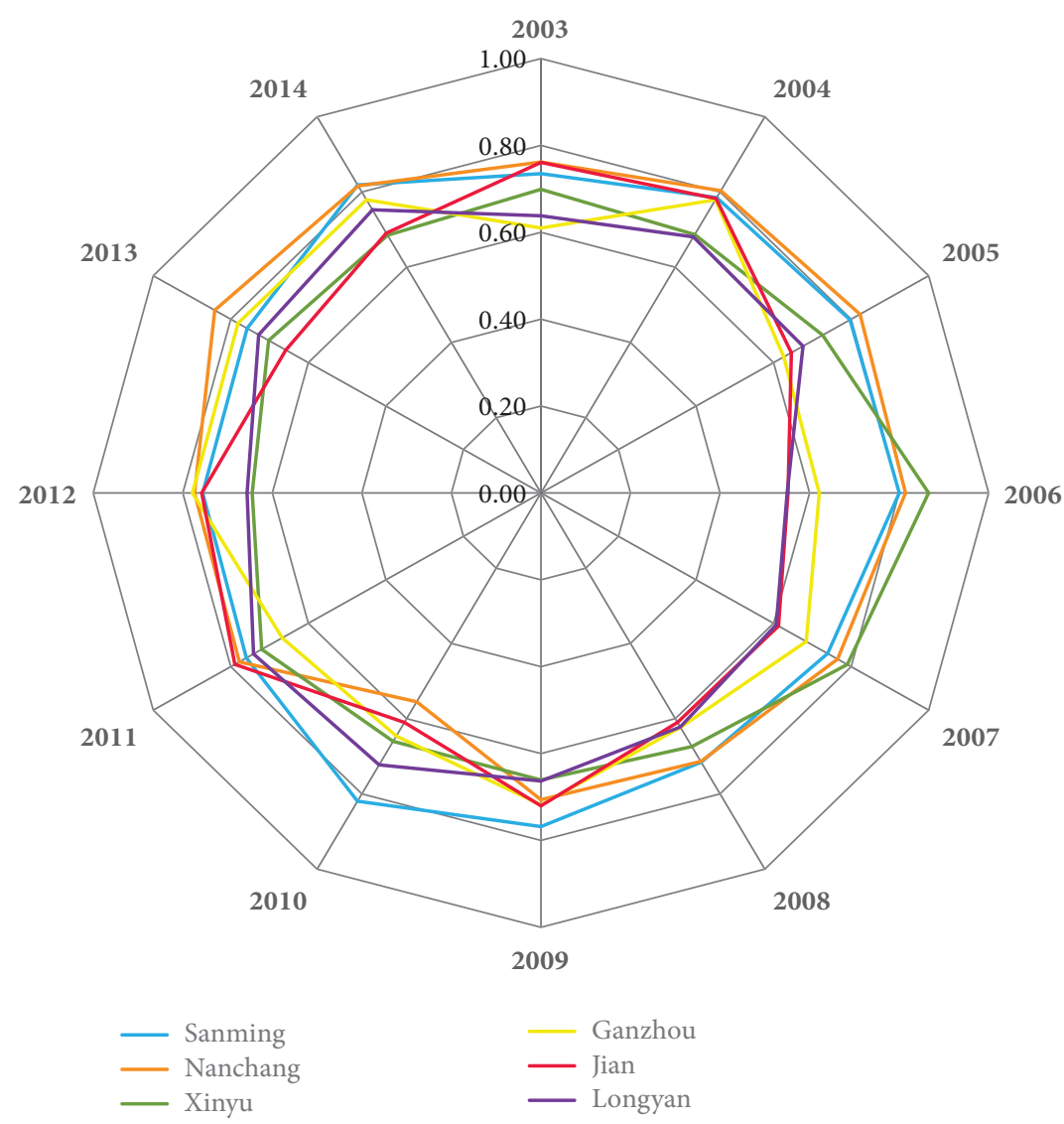

FIgURE 5: Radar chart of Deng's correlations between Xiamen Port and its dry ports from 2003 to 2014.

TABLE 6: Results and rankings of Deng's correlations between Xiamen Port and its dry ports.

\begin{tabular}{lcccccc}
\hline & Sanming & Nanchang & Xinyu & Ganzhou & Jian & Longyan \\
\hline Grey relational grade & 0.77 & 0.76 & 0.71 & 0.69 & 0.68 & 0.67 \\
Ranking & 1 & 2 & 3 & 4 & 5 & 6 \\
\hline
\end{tabular}

Through equalization of Deng's correlations between Xiamen Port and Sanming Dry Port from 2003 to 2014, the final correlation result is 0.77 . We can use the same method to calculate Deng's correlations for other five dry ports, and the overall results are as shown in Table 6 .

Figure 6 shows the histogram of six dry ports' Deng's correlations based on the data in Table 6 . There are obvious regional differences in correlations between Xiamen Port and its dry ports, namely, Xiamen Port's correlations with Sanming and Nanchang are above 0.75 , while those with Xinyu, Ganzhou, Jian, and Longyan are between 0.65 and 0.75 , lower than those of Sanming and Nanchang.

4.3.2. Grey Absolute Correlation Grade Calculation. If we take dry ports' regional GDP and Xiamen Port's cargo transport volume as examples for the calculation of absolute correlation, it is necessary to comprehensively consider the overall conditions of the six dry ports from 2003 to 2014 . Then we can calculate the absolute correlation between dry ports' regional GDP and Xiamen Port's container transport volume. The two sets of seaport cargo transport volume and

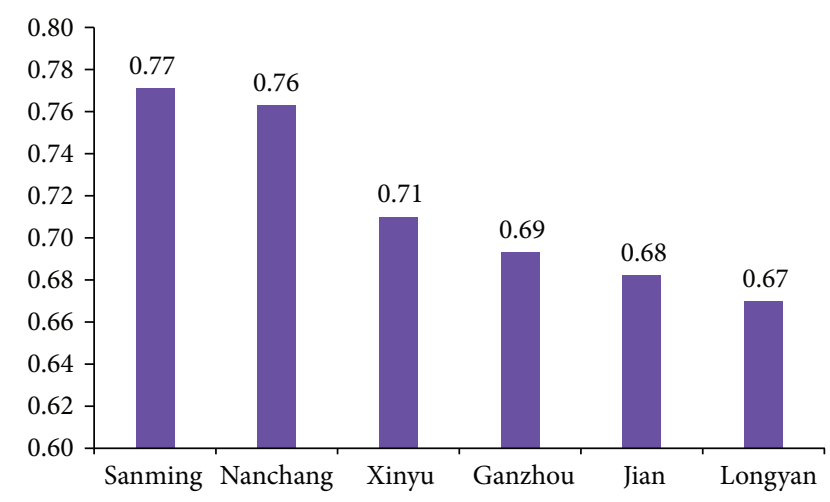

Figure 6: Deng's correlations between Xiamen Port and its dry ports.

container transport volume indicators mapped onto the six dry ports form 12 pieces of data, and the final results can be obtained by calculating the data's weighted averages, namely, the absolute correlation between dry ports' regional GDP and 
TABle 7: Raw data of Xiamen Port's cargo throughput and its dry ports' regional GDP.

\begin{tabular}{lccccccc}
\hline & $\mathrm{xt}(1)$ & $\mathrm{d} 1 \mathrm{t}(1)$ & $\mathrm{d} 2 \mathrm{t}(1)$ & $\mathrm{d} 3 \mathrm{t}(1)$ & $\mathrm{d} 4 \mathrm{t}(1)$ & $\mathrm{d} 5 \mathrm{t}(1)$ & $\mathrm{d} 6 \mathrm{t}(1)$ \\
\hline Y1 & 3403.88 & 321.64 & 290.83 & 641.02 & 344.82 & 109.10 & 205.00 \\
Y2 & 4261.37 & 376.58 & 348.28 & 770.46 & 398.01 & 242.86 \\
Y3 & 4770.76 & 392.08 & 385.22 & 1007.70 & 500.31 & 17.00 & 303.14 \\
Y4 & 7792.07 & 451.59 & 448.64 & 1184.57 & 582.34 & 214.27 & 351.78 \\
Y5 & 8117.20 & 551.32 & 556.03 & 1390.10 & 701.68 & 278.12 & 406.01 \\
Y6 & 9701.96 & 666.92 & 672.85 & 1660.08 & 834.77 & 402.32 & 505.00 \\
Y7 & 11096.28 & 734.24 & 748.45 & 1837.50 & 940.02 & 484.17 \\
Y8 & 12728.05 & 972.71 & 991.49 & 2207.11 & 1119.47 & 631.22 & 720.53 \\
Y9 & 15653.55 & 1231.17 & 1259.87 & 2688.87 & 1335.98 & 779.21 \\
Y10 & 17227.32 & 1339.29 & 1374.65 & 3000.52 & 1508.43 & 830.32 \\
Y11 & 19087.83 & 1477.59 & 1479.90 & 3336.03 & 1673.31 & 845.07 & 1006.26 \\
Y12 & 20503.96 & 1621.21 & 1621.58 & 3667.96 & 1843.59 & 900.27 & 1123.90 \\
\hline
\end{tabular}

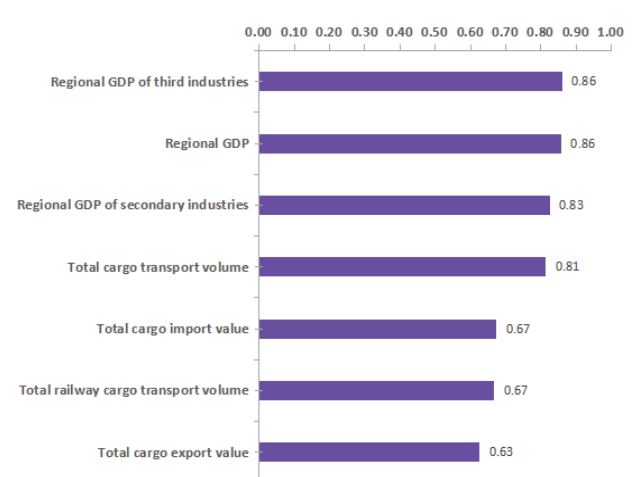

Figure 7: Correlations between seaport's indicators and its dry ports' indicators.

Xiamen Port's cargo transport volume. The same method can be used to process the six dry ports' other indicators. The raw data of Xiamen Port's cargo throughput and its six dry ports' regional GDP from 2003 to 2014 are shown in Table 7, with $\mathrm{i}=1,2, \ldots 6$ representing Sanming, Longyan, Nanchang, Ganzhou, Xinyu, and Jian, respectively.

Input the starting-point annihilating values (see Table 8) into Formula (7) and we can get the absolute correlations between Xiamen Port's cargo throughput and its dry ports' regional GDP, as shown in Table 9.

Similarly, the absolute correlations between Xiamen Port's two indicators and its six dry ports' various indicators are shown in Table 10.

According to Formula (8), the average values of the absolute correlations between Xiamen Port's indicators and its six dry ports' various indicators can be calculated, and the results are shown as follows (see Figure 7).

All correlations between the seaport and its dry port indicators are greater than 0.60 , meaning that the seaport and its dry ports have relatively strong correlations. The correlations of indicators representing economic power, including regional GDP, secondary industry GDP, and third industry GDP, are all above 0.80, far higher than other indicators' correlations with the seaport. Therefore, economic indicators become key factors boosting seaport development, implying that Xiamen Port should positively dedicate itself to economic infrastructure construction in its hinterland areas so as to promote fast economic development there, further expand commodity and cargo transport demands in these areas, and facilitate seaport growth. The hinterland economic indicators are more important for a seaport than the cargo transport volume indicator, indicating that a seaport should pay attention to regional economic construction instead of blindly multiplying cargo transport volumes.

4.4. Result Discussions and Policy Suggestion. Conclusions can be drawn based on the calculation of different assessment indicators' correlations between the seaport and its dry ports in Section 4.3.

Deng's correlation results show that, among the six dry ports, Sanming and Nanchang dry ports have higher correlations with Xiamen Port, with their correlations higher than 0.75 . This means that it is necessary to give priority to development of the two dry ports, such as taking Sanming and Nanchang as core logistics collection and distribution centers in Fujian and Jiangxi provinces, respectively, and accelerating infrastructure construction at the two dry ports, so as to facilitate cargo transport in these areas. But Sanming and Nanchang dry ports follow different development paths. According to the raw data, the railway cargo transport volume from Nanchang Dry Port to Xiamen Port was very low, only 1.82 million tonnes in 2014 , one-fifth of that for Sanming. Therefore, it is necessary to accelerate the sea-railway combined transport construction between Xiamen Port and Nanchang Dry Port. Xiamen Port has lower correlations with the other four dry ports. Ganzhou and Jian dry ports have close cooperation with seaports including Huizhou and Shekou ports in Guangdong province, and the competition between those seaports and Xiamen Port for cargo sources is fierce. Among the six dry ports, Jian Port has the lowest total cargo transport volume and railway cargo transport volume, as shown in the raw data, namely, 54.57 million tonnes and 3.08 million tonnes, respectively, resulting in its lower correlation with Xiaman Port. Restricted by the 
TABLE 8: The starting-point annihilating values for Xiamen Port's cargo throughput and its dry ports' regional GDP.

(a)

\begin{tabular}{|c|c|c|c|c|c|c|c|}
\hline & $\mathrm{x}^{\prime} \mathrm{t}(1)$ & $\mathrm{d}^{\prime} 1 \mathrm{t}(1)$ & $\mathrm{d}^{\prime} 2 \mathrm{t}(1)$ & $\mathrm{d}^{\prime} 3 \mathrm{t}(1)$ & $\mathrm{d}^{\prime} 4 \mathrm{t}(1)$ & $\mathrm{d}^{\prime} 5 \mathrm{t}(1)$ & $\mathrm{d}^{\prime} 6 \mathrm{t}(1)$ \\
\hline $\mathrm{Y} 1$ & 1.00 & 1.00 & 1.00 & 1.00 & 1.00 & 1.00 & 1.00 \\
\hline $\mathrm{Y} 2$ & 1.25 & 1.17 & 1.20 & 1.20 & 1.15 & 1.23 & 1.18 \\
\hline Y3 & 1.40 & 1.22 & 1.32 & 1.57 & 1.45 & 1.63 & 1.48 \\
\hline Y4 & 2.29 & 1.40 & 1.54 & 1.85 & 1.69 & 1.96 & 1.72 \\
\hline Y5 & 2.38 & 1.71 & 1.91 & 2.17 & 2.03 & 2.55 & 1.98 \\
\hline Y6 & 2.85 & 2.07 & 2.31 & 2.59 & 2.42 & 3.69 & 2.46 \\
\hline Y7 & 3.26 & 2.28 & 2.57 & 2.87 & 2.73 & 4.44 & 2.85 \\
\hline Y8 & 3.74 & 3.02 & 3.41 & 3.44 & 3.25 & 5.79 & 3.51 \\
\hline Y9 & 4.60 & 3.83 & 4.33 & 4.19 & 3.87 & 7.14 & 4.29 \\
\hline Y10 & 5.06 & 4.16 & 4.73 & 4.68 & 4.37 & 7.61 & 4.91 \\
\hline Y11 & 5.61 & 4.59 & 5.09 & 5.20 & 4.85 & 7.75 & 5.48 \\
\hline Y12 & 6.02 & 5.04 & 5.58 & 5.72 & 5.35 & 8.25 & 6.06 \\
\hline
\end{tabular}

(b)

\begin{tabular}{|c|c|c|c|c|c|c|c|}
\hline & $x^{\prime \prime} t(1)$ & $\mathrm{d}^{\prime \prime} 1 \mathrm{t}(1)$ & $\mathrm{d}^{\prime \prime} 2 \mathrm{t}(1)$ & $\mathrm{d}^{\prime \prime} 3 \mathrm{t}(1)$ & $\mathrm{d}^{\prime \prime} 4 \mathrm{t}(1)$ & $\mathrm{d}^{\prime \prime} 5 \mathrm{t}(1)$ & $\mathrm{d}^{\prime \prime} 6 \mathrm{t}(1)$ \\
\hline Y1 & 0.00 & 0.00 & 0.00 & 0.00 & 0.00 & 0.00 & 0.00 \\
\hline Y2 & 0.25 & 0.17 & 0.20 & 0.20 & 0.15 & 0.23 & 0.18 \\
\hline Y3 & 0.40 & 0.22 & 0.32 & 0.57 & 0.45 & 0.63 & 0.48 \\
\hline Y4 & 1.29 & 0.40 & 0.54 & 0.85 & 0.69 & 0.96 & 0.72 \\
\hline Y5 & 1.38 & 0.71 & 0.91 & 1.17 & 1.03 & 1.55 & 0.98 \\
\hline Y6 & 1.85 & 1.07 & 1.31 & 1.59 & 1.42 & 2.69 & 1.46 \\
\hline Y7 & 2.26 & 1.28 & 1.57 & 1.87 & 1.73 & 3.44 & 1.85 \\
\hline Y8 & 2.74 & 2.02 & 2.41 & 2.44 & 2.25 & 4.79 & 2.51 \\
\hline Y9 & 3.60 & 2.83 & 3.33 & 3.19 & 2.87 & 6.14 & 3.29 \\
\hline Y10 & 4.06 & 3.16 & 3.73 & 3.68 & 3.37 & 6.61 & 3.91 \\
\hline Y11 & 4.61 & 3.59 & 4.09 & 4.20 & 3.85 & 6.75 & 4.48 \\
\hline Y12 & 5.02 & 4.04 & 4.58 & 4.72 & 4.35 & 7.25 & 5.06 \\
\hline
\end{tabular}

TABle 9: Grey absolute correlations between Xiamen Port's cargo throughput and its dry ports' regional GDP.

\begin{tabular}{lcccccc}
\hline & $\mathrm{i}=1$ & $\mathrm{i}=2$ & $\mathrm{i}=3$ & $\mathrm{i}=4$ & $\mathrm{i}=5$ & $\mathrm{i}=6$ \\
\hline$\gamma^{\prime}(\mathrm{x}(1), \operatorname{di}(1))$ & 0.85 & 0.92 & 0.94 & 0.90 & 0.84 & 0.95 \\
\hline
\end{tabular}

less advanced regional economic development in Xinyu and Longyan dry port areas, dry ports there started late and have unsatisfactory correlations with Xiamen Port. The average annual cargo export values from Xinyu and Longyan dry ports were lower than US\$1 billion, while those at other dry ports (except Sanming) were all far higher than US\$1 billion, and Nanchang Dry Port even registered an average annual export value of US\$3.6 billion. Xiamen Port is advised to launch preferential import and export policies to attract the lost cargo sources from areas including Ganzhou and Jian and carry out economic infrastructure construction in its hinterland areas where Xinyu and Longyan dry ports located to improve the poor economic strength and expand regional commodity and cargo transport demands.

The absolute correlation results show that the correlations of economic-strength-representing indicators of dry ports with Xiamen Port, including regional GDP, secondary industry GDP, and third industry GDP, are all greater than
0.80 , significantly higher than the correlations of dry ports' other indicators with Xiamen Port. Therefore, economic indicators become key factors boosting seaport development, and economic infrastructure construction in the hinterland areas where dry ports are located will effectively upgrade the seaport's comprehensive competitiveness. The correlations of dry ports' foreign trade import and export values with Xiamen Port are all lower than 0.70, which means that the less foreign trade activities in the six dry port areas led to these indicators' low correlations with Xiamen Port. With this regard, it is necessary to encourage dry port hinterland areas to promote foreign trade by introducing macropreferential foreign trade policies. The correlation of dry ports' total cargo transport volume indicator with Xiamen Port stands at 0.81 , higher than their railway transport volume indicator's correlation of 0.67 . Therefore, it is necessary to accelerate allocation of special cargo transport trains between Xiamen Port and its dry ports and expand railway transport capacity 


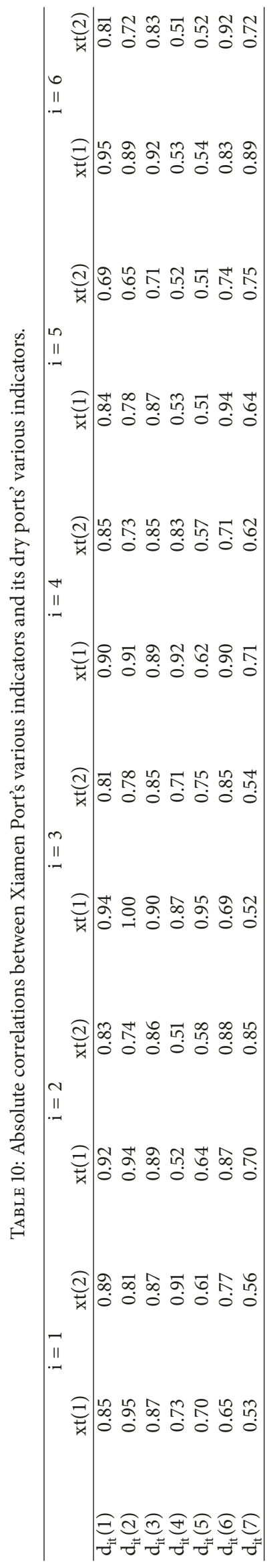


to enrich combined transport forms at Xiamen Port, so as to further promote the win-win cooperation between Xiamen Port and its dry ports.

\section{Conclusions and Future Research}

Dry ports not only expand a seaport's hinterland areas and increase its cargo sources, but also simplify import and export procedures. The smooth coordination between a seaport and its dry ports directly impacts the effective operation throughput the logistics supply chain. Driven by global economic integration and inland-oriented logistics services, the cooperation between seaports and their dry ports is getting increasingly close. Therefore, the study on the relevance between a seaport and its dry ports becomes crucial and their interactions deserve further improvements.

In the correlation study, it was difficult to conduct quantitative research because of the incomplete data for the classification of primary and secondary factors in the development of a seaport and its dry ports as well as various factors' roles in the system. The GRA method makes up for the above-mentioned deficiencies just right, as the GRA method is applicable when only a small number of irregular samples are available. This has unique advantages in the study on the correlations between a seaport and its dry ports. This paper is structured based on the GRA method to fully verify the higher correlations between a seaport and its dry ports, which has provided a basis for reaching the conclusions in the paper.

According to our research results, the following is a summary of relevant conclusions. There are generally strong correlations between Xiamen Port and the economic hinterlands where its dry ports are located, but the dry ports have evident regional differences. The correlations of dry ports' economic indicators with Xiamen Port are higher than those of cargo transport volume indicators, making economic indicators the key factors driving fast development of the seaport. With regard to the issues arising in interactions between the seaport and its dry ports, we suggest Xiamen Port maintain existing cargo sources through preferential foreign trade policies and encourage its inland regions to carry out foreign trade activities and accelerate sea-railway combined transport construction. The paper has made contributions in three aspects: (1) build an assessment indicator system on correlations between a seaport and its dry ports, which can provide a basis for relevant studies, (2) adopt the GRA method to study correlations between a seaport and its dry ports, which can avoid the deficiencies of mathematical statistics, and (3) put forward policies on joint development of a seaport and its dry ports.

Based on this study, it is necessary to constantly improve research on correlations between a seaport and its dry ports, and the following studies are expected in the future: (1) expand the assessment indicator system on correlations between a seaport and its dry ports to include more variables, (2) analyze other correlations through the GRA method in addition to Deng's correlation and absolute correlation, and (3) investigate the industry and policies to offer bases for studying the roles of the correlations between a seaport and its dry ports.

\section{Data Availability}

The data used to support the findings of this study are available from the corresponding author upon request.

\section{Conflicts of Interest}

The authors declare that there are no conflicts of interest regarding the publication of this paper.

\section{Authors' Contributions}

Jihong Chen, Yijie Fei, and Chutao Jing conceived the research idea, established the mathematical models, and cowrote the paper. Fangwei Zhang performed data analysis and cowrote and revised the paper.

\section{Acknowledgments}

The research is supported by Shanghai Pujiang Program (17PJC053), the National Natural Science Foundation of China (Grants nos. 51409157 and 515083192), Program of Humanities and Social Science of Ministry of Education of China (14YJC630008), and Shanghai Science \& Technology Committee Research Project (15590501700 and 17040501700).

\section{References}

[1] A. Jaržemskis and A. V. Vasiliauskas, "Research on dry port concept as intermodal node," Transport, vol. 22, no. 3, pp. 207213, 2007.

[2] V. Roso, J. Woxenius, and K. Lumsden, "The dry port concept: connecting container seaports with the hinterland," Journal of Transport Geography, vol. 17, no. 5, pp. 338-345, 2009.

[3] P. Coto-Millán, M. A. Pesquera, and J. Castanedo, Eds., Essays on Port Economics, Springer Science \& Business Media, 2010.

[4] V. Roso, "Factors influencing implementation of a dry port," International Journal of Physical Distribution and Logistics Management, vol. 38, no. 10, pp. 782-798, 2008.

[5] R. Danielis and T. Gregori, "An input-output-based methodology to estimate the economic role of a port: the case of the port system of the Friuli Venezia Giulia Region, Italy," Maritime Economics \& Logistics, vol. 15, no. 2, pp. 222-255, 2013.

[6] K. Cullinane and G. Wilmsmeier, "The contribution of the dry port concept to the extension of port life cycles," Handbook of Terminal Planning, vol. 49, no. 1, pp. 359-379, 2011.

[7] V. Henttu, L. Lättilä, and O. P. Hilmola, "Financial and environmental impacts of a dry port to support two major Finnish seaports," Lappeenranta University of Technology, Department of Industrial Management, Research Report, vol. 224, p. 141, 2010.

[8] J.-P. Rodrigue, J. Debrie, A. Fremont, and E. Gouvernal, "Functions and actors of inland ports: european and north american dynamics," Journal of Transport Geography, vol. 18, no. 4, pp. 519-529, 2010. 
[9] J. Wei, A. Sun, and J. Zhuang, "The selection of dry port location with the method of Fuzzy-ANP," Advances in Wireless Networks and Information Systems, pp. 265-273, 2010.

[10] G. R. YOchum and V. B. Agarwal, "Economic impact of a port on a regional economy: note," Growth and Change, vol. 18, no. 3, pp. 74-87, 1987.

[11] A. Y. Ng and G. C. Gujar, "Government policies, efficiency and competitiveness: the case of dry ports in India," Transport Policy, vol. 16, no. 5, pp. 232-239, 2009.

[12] V. Henttu, L. Lättilä, and O.-P. Hilmola, "Optimization of relative transport costs of a hypothetical dry port structure," Transport and Telecommunication Journal, vol. 12, no. 2, pp. 1219, 2011.

[13] S. Awad-Núñez, N. González-Cancelas, and A. CamareroOrive, "Application of a model based on the use of DELPHI methodology and multicriteria analysis for the assessment of the quality of the spanish dry ports location," Procedia-Social and Behavioral Sciences, vol. 162, pp. 42-50, 2014.

[14] J. Woxenius, V. Roso, and K. Lumsden, "The dry port conceptconnecting seaports with their hinterland by rail," ICLSP Conference Proceedings, pp. 305-319, 2004.

[15] A. Veenstra, R. Zuidwijk, and E. Van Asperen, "The extended gate concept for container terminals: Expanding the notion of dry ports," Maritime Economics \& Logistics, vol. 14, no. 1, pp. 1432, 2012.

[16] D. Ambrosino and A. Sciomachen, "Location of mid-range dry ports in multimodal logistic networks," Procedia-Social and Behavioral Sciences, vol. 108, pp. 118-128, 2014.

[17] Q. Li and X. M. Chen, "Dry ports' site selection in jiangxi province based on principal component analysis," Shipping Management, vol. 38, no. 2, pp. 31-33, 2016.

[18] Z. P. Song, "Dry ports' site selection in henan province based on factor analysis," Port Economy, vol. 8, pp. 21-23, 2016.

[19] K. Tan, Study on Site Selection of Guangzhou Port's Dry Port Group, Southwest Jiaotong University, 2009.

[20] L. Huang, J. H. Zheng, and W. Wang, "Study on dry port's site selection based on analytic hierarchy process," Logistics Technology, vol. 32, no. 1, pp. 153-156, 2013.

[21] B. Ka, "Application of fuzzy AHP and ELECTRE to China dry port location selection," Asian Journal of Shipping and Logistics, vol. 27, no. 2, pp. 331-354, 2011.

[22] A. H. Kashani, A. N. Nodehi, and S. Bandpey, "Prioritization of dry ports by using pair comparison technique to enhance AHP," International Journal of Business and Commerce, vol. 3, no. 7, p. 34, 2014.

[23] M. Wu, "Study on dry port's site selection based on AHP multilayer fuzzy comprehensive assessment," Transportation Science \& Technology, vol. 2, pp. 176-179, 2014.

[24] Z. M. Zhang, "Application of fuzzy c-means clustering in inland dry port's site selection," Journal of Shanghai Maritime University, vol. 29, no. 4, pp. 34-38, 2008.

[25] H. W. Zou, Study on Inland Port's Site Selection Planning in Northeast China Region, Dalian Maritime University, 2009.

[26] Q. L. Zeng and Y. Wang, "Network layout of dry port group in economic zone on the west coast of the taiwan strait-based on fuzzy clustering method and spss17. 0 software," Science Technology and Industry, vol. 10, no. 10, pp. 1-4, 2010.

[27] J. C. Song, Study on Qingdao Dry Port's Site Selection Based on Fuzzy C-means Clustering Method, Ocean University of China, 2011.
[28] Z. M. Zhang and B. Han, "Study on dry port's site selection in pan pearl river delta region under industry transfer background," Railway Transport and Economy, vol. 37, no. 1, pp. 3844, 2015.

[29] C. J. Liang, J. J. Jia, D. H. Xu, and B. Lu, "Comprehensive application of two kinds of models in inland dry port's site selection," Journal of Chongqing Jiaotong University, vol. 35, no. 1, pp. 177-183, 2016.

[30] P. M. Panayides and D.-W. Song, "Port integration in global supply chains: measures and implications for maritime logistics," International Journal of Logistics Research and Applications, vol. 12, no. 2, pp. 133-145, 2009.

[31] V. Henttu and O.-P. Hilmola, "Financial and environmental impacts of hypothetical Finnish dry port structure," Research in Transportation Economics, vol. 33, no. 1, pp. 35-41, 2011.

[32] Q. Zeng, M. J. Maloni, J. A. Paul, and Z. Yang, "Dry port development in China: motivations, challenges, and opportunities," Transportation Journal, vol. 52, no. 2, pp. 234-263, 2013.

[33] V. Roso, "Sustainable intermodal transport via dry portsimportance of directional development," World Review of Intermodal Transportation Research, vol. 4, no. 2-3, pp. 140-156, 2013.

[34] R. Van den Berg and P. W. De Langen, "Hinterland strategies of port authorities: a case study of the port of barcelona," Research in Transportation Economics, vol. 33, no. 1, pp. 6-14, 2011.

[35] R. Bergqvist and J. Woxenius, "The development of hinterland transport by rail-the story of scandinavia and the port of Gothenburg," Journal of Interdisciplinary Economics, vol. 23, no. 2, pp. 161-175, 2011.

[36] R. Aronietis, T. Pauwels, T. Vanelslander, J. Gadziński, A. Golędzinowska, and R. Wasil, "Port hinterland connections: a comparative study of Polish and Belgian cases," Procedia-Social and Behavioral Sciences, vol. 20, pp. 59-68, 2011.

[37] J. I. Castillo-Manzano, F. González-Laxe, and L. LópezValpuesta, "Intermodal connections at Spanish ports and their role in capturing hinterland traffic," Ocean \& Coastal Management, vol. 86, pp. 1-12, 2013.

[38] A. Bask, V. Roso, D. Andersson, and E. Hämäläinen, "Development of seaport-dry port dyads: Two cases from Northern Europe," Journal of Transport Geography, vol. 39, pp. 85-95, 2014. 


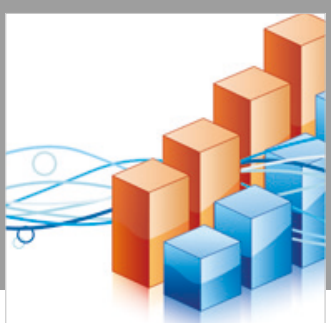

Advances in

Operations Research

\section{-n-m}
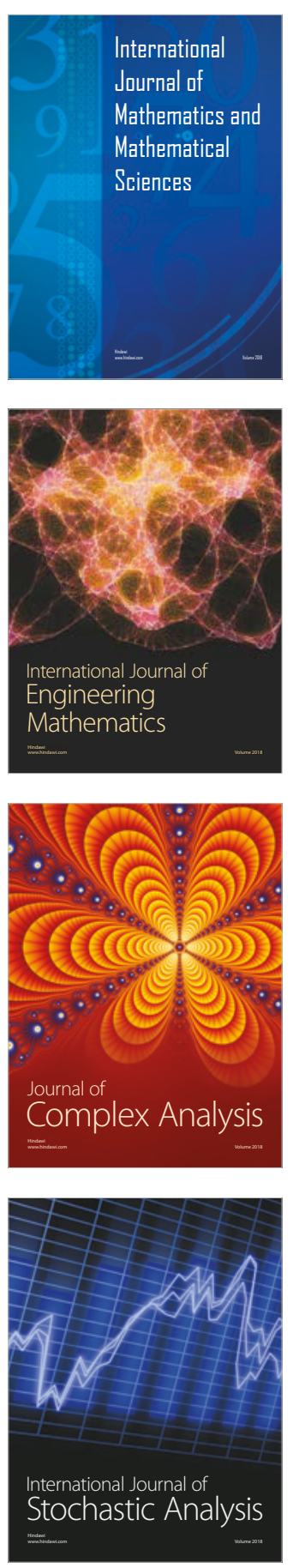
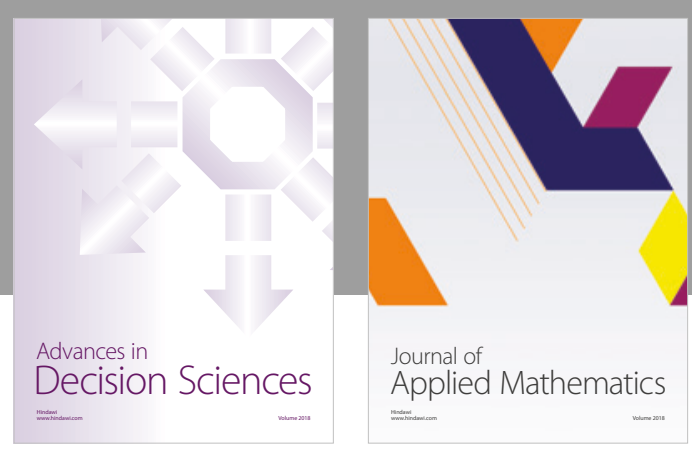

Journal of

Applied Mathematics
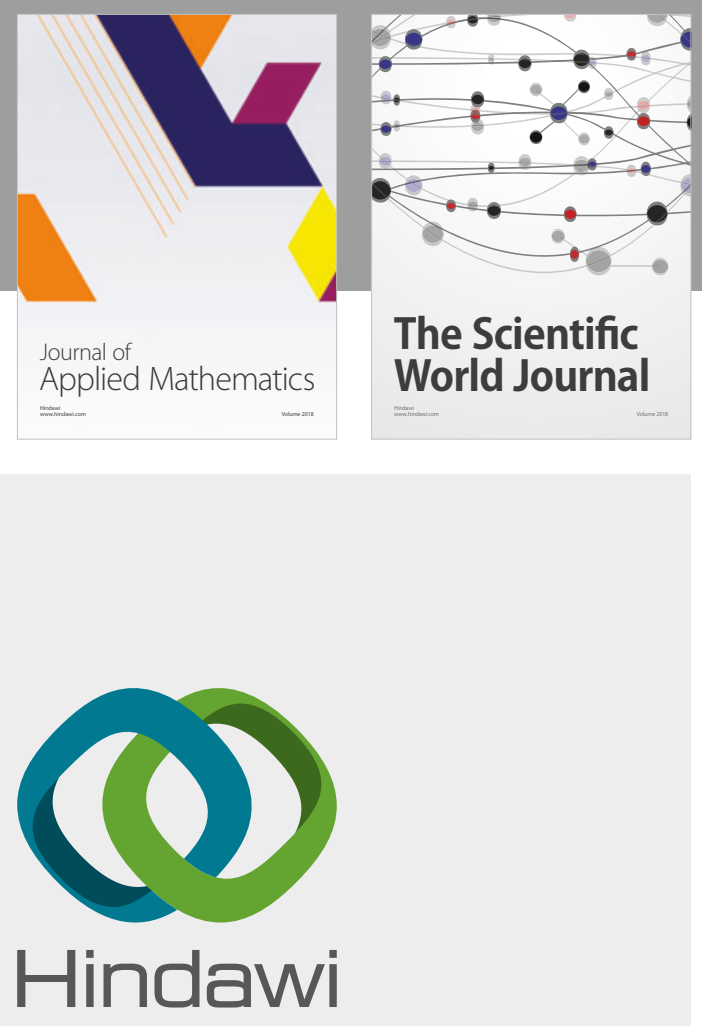

Submit your manuscripts at

www.hindawi.com

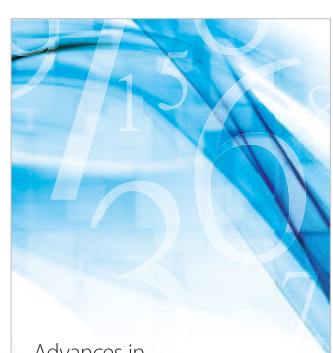

Advances in
Numerical Analysis
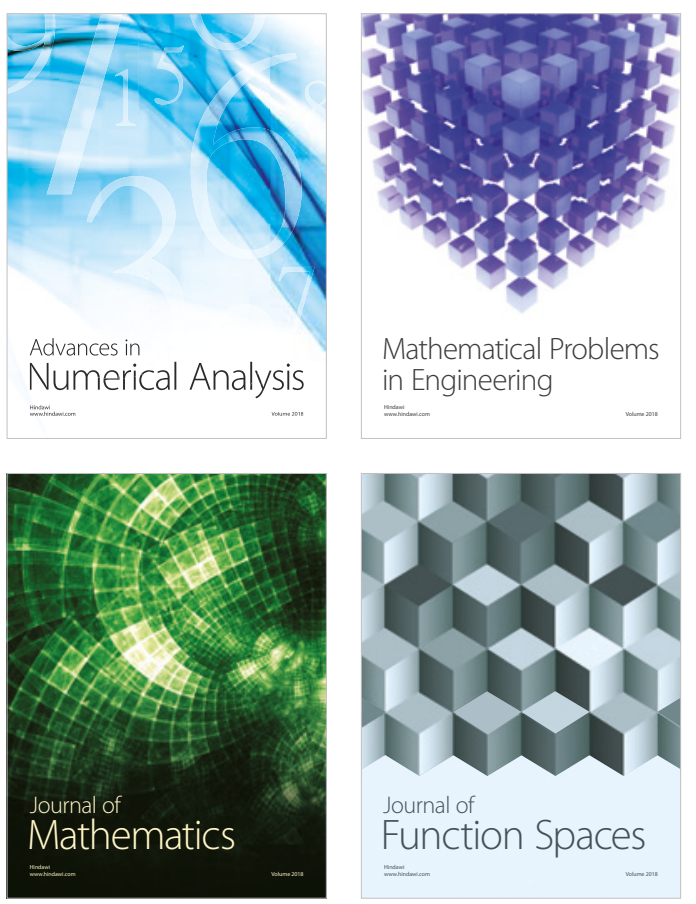

Mathematical Problems in Engineering

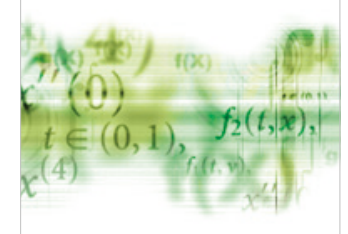

International Journal of

Differential Equations

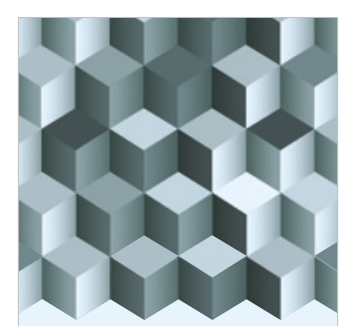

Journal of

Function Spaces

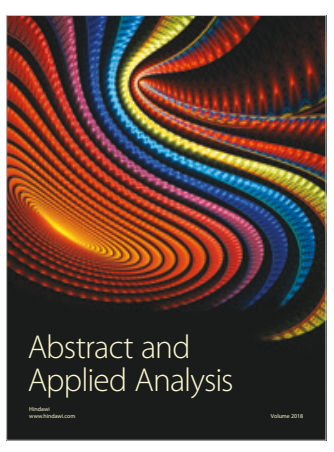

The Scientific

World Journal

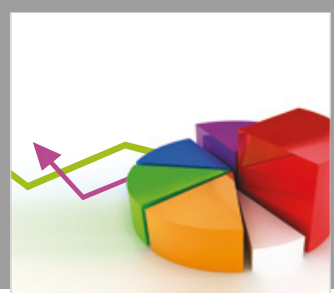

Journal of

Probability and Statistics
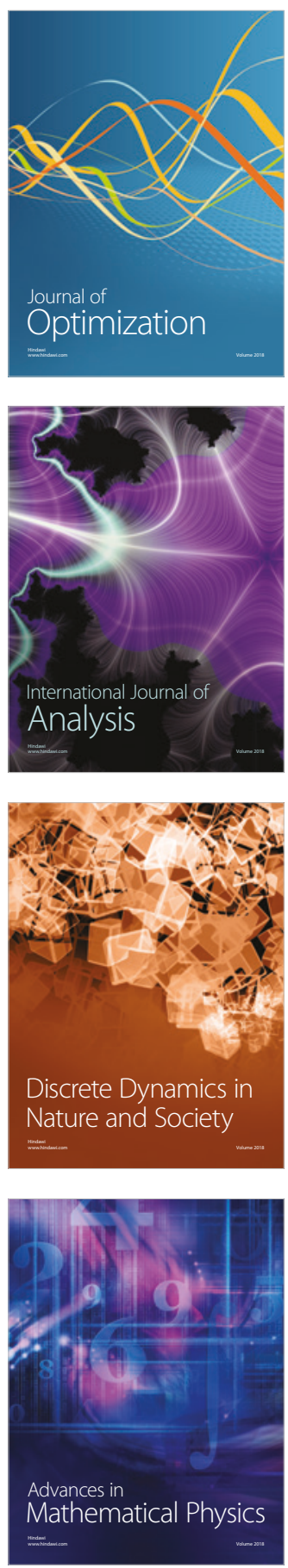